\title{
Risk Factors Associated with Spontaneous Abortion at Woman's Health Hospital Assiut University.
}

\author{
Ebtesam Elsayed Eldabae ${ }^{1}$, Nabila Taha ${ }^{2}$, Mansour Ahmed Khalifa ${ }^{3}$, Amal Gamal ${ }^{4}$. \\ 1. Specialist Nurse, Woman's Health Hospital, Assiut University, Egypt. \\ 2. Professor of Obstetric \& Gynecological Nursing, Faculty of Nursing, Assiut University Egypt. \\ 3. Lecturer of Obstetrics \& Gynecology, Faculty of Medicine, Assiut Univeraity, Egypt. \\ 4. Assistant Professor of Obstetric \& Gynecological Nursing, Faculty of Nursing, Menofia University, Egypt.
}

\begin{abstract}
Background, Spontaneous abortion is a failed intrauterine pregnancy that ends before 20 weeks of gestation. Many factors can lead to it such as: age, smoking, etc. This study aimed to identify risk factors associated with spontaneous abortion. A descriptive study was the design. Purposive sample of 200 women diagnosed as spontaneous abortion were recruited. The setting was the emergency unit, at Woman's Health Hospital, Assiut university .The tool of data collection was an interview questionnaire which contains personal data, menstrual, obstetrical, medical and current history, other risk factors. The results of the study showed that $81 \%$ of study group were aged between 20-35years old, 54.5\% were no and low level of education, $90 \%$ were from rural areas $\& 91 \%$ were housewives. The late abortion represented $57.5 \%$, while the missed abortion was the most frequent type of spontaneous abortions (38\%).Nearly half of the study group (47.5\%) exposed to passive smoking. The study concludes that the risk factors relating to the spontaneous abortion were rural residency, low level of education, short spacing, exposure to passive smoking \& previous abortion. The study recommended to increase the women' awareness about the risk factors of spontaneous abortion. Encouraging early \& regular antenatal care (ANC).Encouraging preconception counseling.
\end{abstract}

\section{Keywords: Risk factors \& Spontaneous Abortion.}

\section{Introduction}

Spontaneous abortion is the death of embryo in the uterus without cause before 20 weeks of gestation. Also, considered as the most common complication during early pregnancy which complicate $15-20 \%$ of pregnant women. Moreover, $80 \%$ of early pregnancy loss occurs in the first trimester; less than 13 week gestation. The risk of spontaneous abortion decreases after 12 weeks gestation (Dugas\&Slane,2019, John, 2016\&Peruzzi,2016).

Abortion is considered a major reproductive health matter acts as a health risk factor for mother's wellbeing and threatened their lives and comfort (Jibril et al., 2014).

Spontaneous abortion is the most common type of pregnancy loss, affecting around one fourth of all pregnancies. It considers a very difficult and distressing experience, affecting many women and their partners (Spontaneous abortion association, 2015). Spontaneous abortion risk increased with the presence of more than one risk factor and at the same time considers preventable (Nilsson et al., 2014). It includes, threatened spontaneous abortion; characterized by mild bleeding with little or no pain, and closed cervix. Inevitable spontaneous abortion; presents with heavy bleeding with clots, pain and opened cervix. The pregnancy will not continue and will proceed to incomplete, complete or missed spontaneous abortions (Catalano et al., 2017, \& Hobel et al., 2016).

Risk factors of spontaneous abortion are embryonic or fetal chromosomal abnormality; make it impossible for the embryo to develop (Tulandi\& AlFozan, 2019, Romero et al., 2015).

Risk factors of spontaneous abortion include fetal, maternal, paternal and environmental factors. Smoking, alcohol drinking, uncontrolled diabetes hypertension, obesity, age, cervical incompetence, low progesterone level, occupational stress and lifestyle considered risk factors (Center for disease control \& prevention, 2012\& Costello, 2013), (Rodriguez, 2014 \& 2015 \& Pour, 2015).

Low income levels were associated with poor housing, nutrition and health care access, as well as increasing the risk of spontaneous abortion. Maternal educational level influenced pregnancy outcomes through access to health services and care strategies for both mother and her fetus (Ameen \& Tawfeeq, 2015).

Vitamins or folic acid supplement before pregnancy can greatly lower the chances of spontaneous abortion and certain birth defects. Spontaneous abortions could be prevented if the maternal age at conception is between 25 and 29 years, and if alcohol was stopped. A pregnant woman who develops any signs or symptoms of threatened spontaneous abortion instructed to contact her health care 
providers directly (Magnus et al., 2019, Catalano et al., 2017).

Although the cause of spontaneous abortion is usually out of a woman's control, she is having a chance for successful pregnancy by changing her lifestyle through eating healthy diet, avoiding obesity, controlling chronic diseases, avoiding smoking, avoiding exposure to radiography, limiting intake of caffeine and taking folic acid daily (Kamble \& Banerjee, 2017).

Improvement in the diagnosis and management of early pregnancy loss is of vital importance, to reduce the incidence of the associated bleeding, infection which may occur, psychological morbidity and avoid maternal mortality (Smith et al., 2019, National institute for health and care excellence, 2012).

\section{Aim of the study}

This study aimed to identify risk factors associated with spontaneous abortion.

\section{Significance of the study}

Danielsson, (2015) found a total spontaneous abortion rate of $31 \%$. As spontaneous abortions are considered irreversible, prevention is probably the only way to intervene in this problem (Kong, et al, 2010). Modification of risk factors by acting before and during pregnancy could lead to a prevention of 14.7 and $12.5 \%$ of the spontaneous abortions, respectively (Nilsson, et al, 2014)(Wahabi, et al, 2011). Thus, this study contributed to a better understanding of the risk factors for spontaneous abortion and it will add to the body of knowledge related to spontaneous abortion.

\section{Research question}

What are the risk factors associated with spontaneous abortion at woman's health hospital, Assuit University?

\section{Patients \& Methods}

Research design

A descriptive study was used to achieve the aim of the current study.

\section{Setting}

This study conducted at the emergency units (at labor ward), Woman's Health hospital, Assiut University.

\section{Subjects}

Purposive Sample of 200 women diagnosed as spontaneous abortion were recruited.

\section{Sampling}

Sample size estimated for frequency in a population $\mathrm{N}=[\operatorname{deff} * n p(1-\mathrm{p})] /\left[\left(\mathrm{d}^{\wedge} 2 / \mathrm{z}^{\wedge} 2 *(\mathrm{n}-1)+\mathrm{p} *(1-\mathrm{p})\right]\right.$ resulted from open epi, version 2 , open source calculator SPSS proper at confidence level $(95 \%)=$ 196 aborted women for accuracy.

\section{Inclusion criteria}

-Women who had spontaneous abortion.

-Women accepted to participate in the study.

Tool of data collection

The data were collected using an interview questionnaire which developed by the researcher based on literature review. The questionnaire consisted of personal data, menstrual history, past obstetrical history, medical history, the current obstetrical history and associated risk factors as age, previous abortion, chronic medical conditions, uterine or cervical problems, smoking, alcohol, invasive prenatal tests, hormonal imbalance, Physical trauma, Sexual trauma, Chromosomal abnormalities, Infectious agents, Stress, Intrauterine device, Medications,(Heavy metals, pesticides, hyperthermia, lead, organic solvents), Conception within 3-6 months after delivery .

\section{Pilot study}

A pilot study was conducted on $10 \%$ (20women) of the sample. The pilot study was carried out to assess the applicability and clarity of the constructed questionnaire, to determine the time needed to answer the questions, and to detect any problems that might arise during the actual collection of data. Thereafter, the necessary modifications and clarifications of some questions were carried out according to the results of the pilot study, and a final form was developed and used in data collection. This sample were excluded from the total sample.

\section{Procedures}

\section{Administrative phase}

First step in the study was obtaining an official permission from the responsible authorities in both Faculty of Nursing. Assiut University \& Women's Health Hospital after explaining the purpose of the study.

\section{Interviewing phase}

Participants women were informed about the purpose of the study, and that the participation is voluntary (they had the right to refuse to participate). Then, oral consent of the participants of the study was obtained before the completion of the interview questionnaire. Moreover, confidentiality of the information was assured. Furthermore, the participants of the study were told that they can refrain from answering any question and they can terminate the interview at any time.

The researcher carried out the interview face-to face with each woman. Risk factors examined were current and past cigarette smoking, exposure to passive smoking at home, current and past caffeine consumption (coffee, tea, and cola consumption), nature of the work, work schedule, child spacing, and obesity. Other factors were also assessed, such as maternal age, regularity of menstrual cycle, 
educational level, past medical and obstetrical history. The questionnaires were obtained through face-to-face interview with each woman individually by the researcher at waiting room in emergency unit before discharge. Each

interview took about 15 minutes. Data were collected from the onset of May to the end of December 2018.

Ethical considerations

The proposal of the study was approved from ethical committee in the Faculty of Nursing, Assiut University. Oral consent was obtained from the participants who were willing to participate in the study. Participants were informed that their participation would be on voluntary basis, and anonymity of the tool and confidentiality of the participants were always maintained.

Statistical analysis

Data were coded, entered, and analyzed using the statistical package for social science (SPSS INC), version 20. Data were presented using statistics in the form of frequencies and percentage. Interval and ratio variables were presented in the form of means and standard deviation .The significance level was chosen as p-value $<0.05$.

\section{Results}

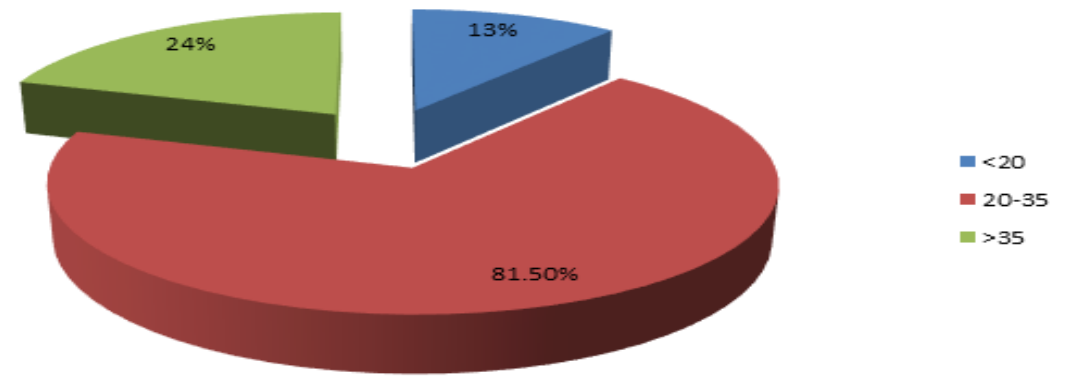

Fig (1): Distribution of the studied women by their age.

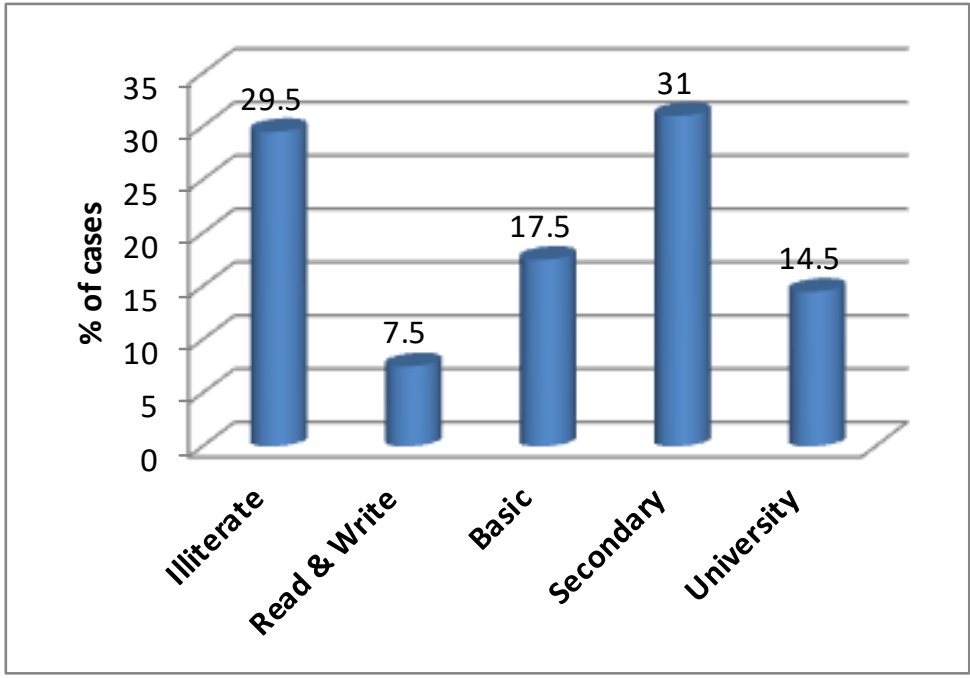

Fig (2): Distribution of the studied women by their education. 


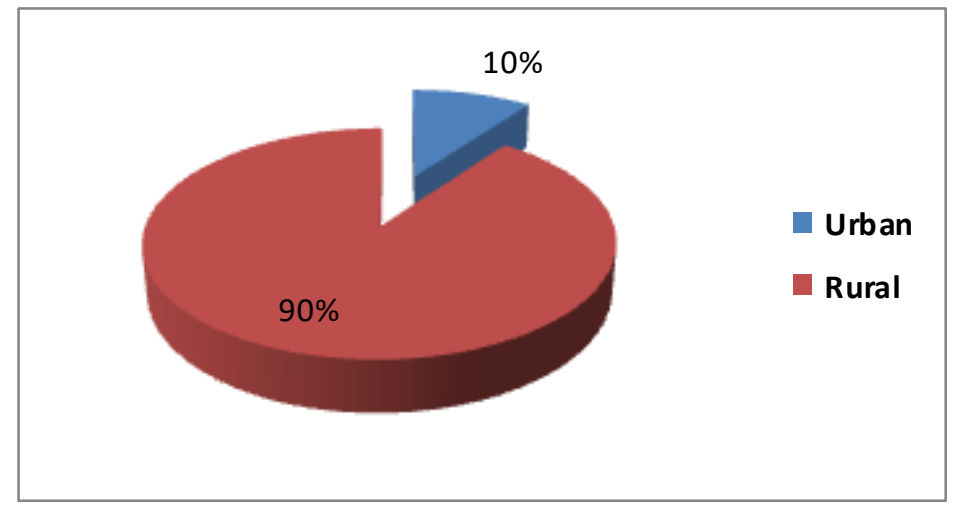

Fig (3): Distribution of the studied women by their residence.

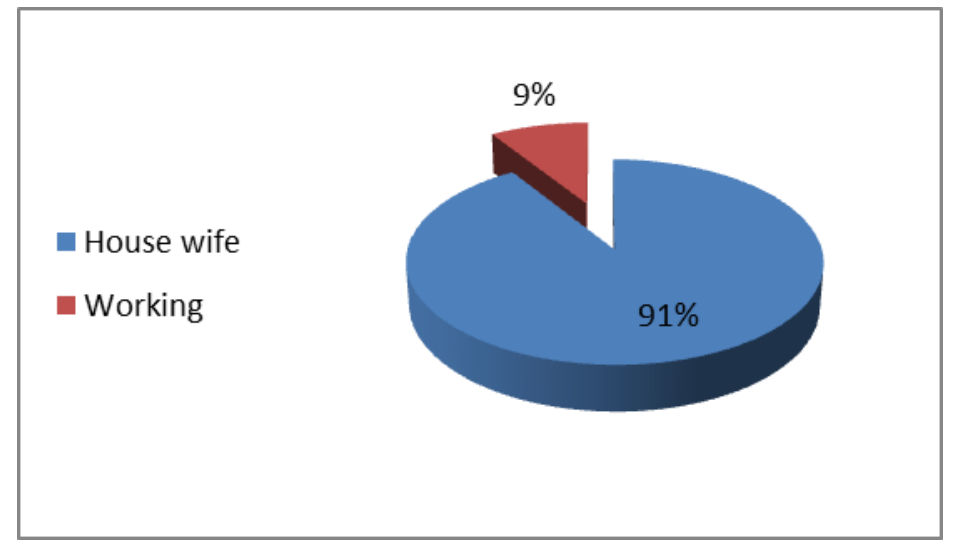

Fig (4): Distribution of the studied women by their occupation.

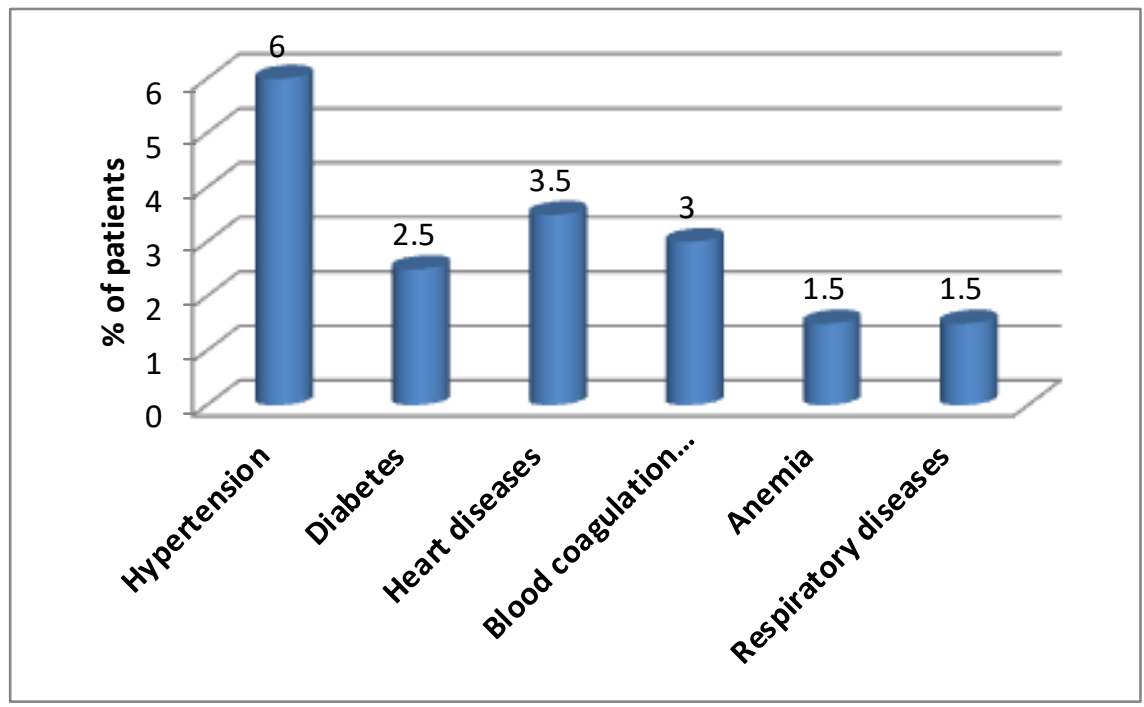

Fig (5): distribution of the study group by their Medical history. 
Table (1): Distribution of the studied women by their past obstetrical history

\begin{tabular}{|c|c|c|}
\hline \multirow{2}{*}{ Past obstetrical history } & \multicolumn{2}{|c|}{$\begin{array}{c}\text { Total } \\
200(100 \%)\end{array}$} \\
\hline & $\mathbf{N}$ & $\%$ \\
\hline $\begin{array}{l}\text { 1-Spacing "mon/s" } \\
\text { - } \quad \text { No } \\
\text { - } \quad \leq 24 \\
\text { - } \quad>24\end{array}$ & $\begin{array}{c}28.48 \pm 4.56 \\
39 \\
92 \\
69\end{array}$ & $\begin{array}{l}19.5 \\
46.5 \\
34.5\end{array}$ \\
\hline $\begin{array}{ll}\text { 2-Grvidity } \\
\bullet & \text { Primi } \\
\text { - } & \text { Multigravida } \\
\text { - } & \text { Grand multigravida }\end{array}$ & $\begin{array}{l}38 \\
84 \\
78\end{array}$ & $\begin{array}{l}19.0 \\
42.0 \\
39.0\end{array}$ \\
\hline $\begin{array}{ll}3-P a r i t y \\
- & \text { Nullipara } \\
\text { - } & \text { Primi } \\
\text { - } & \text { Multipara } \\
\text { - } & \text { Grand multipara }\end{array}$ & $\begin{array}{l}48 \\
31 \\
95 \\
26\end{array}$ & $\begin{array}{l}24.0 \\
15.5 \\
47.5 \\
13.0\end{array}$ \\
\hline $\begin{array}{lc}4 \text { 4-Abortion } \\
\bullet \quad \text { No } \\
-\quad 1-2 \\
-\quad>=3\end{array}$ & $\begin{array}{l}94 \\
86 \\
20\end{array}$ & $\begin{array}{l}47.0 \\
43.0 \\
10.0\end{array}$ \\
\hline
\end{tabular}

Table (2): Distribution of the studied women by their current obstetrical history.

\begin{tabular}{|l|c|c|}
\hline \multicolumn{1}{|c|}{ Current obstetrical history } & \multicolumn{2}{c|}{ Total } \\
& $\mathbf{2 0 0 ( 1 0 0 \% )}$ \\
\cline { 2 - 3 } & $\mathbf{2}$ & \multicolumn{2}{|c|}{$13.70 \pm 3.48$} \\
\hline Mean gestational age & & \\
\hline Types of abortion according to time $\quad$ Early $<=12$ & 85 & 42.5 \\
- $\quad$ Late $>\mathbf{1 2}$ & 115 & 57.5 \\
\hline
\end{tabular}

Table (3): Distribution of studied women according to types of abortion.

\begin{tabular}{|ll|c|c|}
\hline \multirow{2}{*}{ Type of abortion } & \multicolumn{2}{|c|}{$\begin{array}{c}\text { Total } \\
\text { 200(100\%) }\end{array}$} \\
\cline { 3 - 4 } & & $\mathbf{N}$ & \% \\
\hline 1. & Thratened Abortion & 6 & 3.0 \\
2. & Missed abortion & 76 & 38.0 \\
3. Invitable abortion & 68 & 34.5 \\
4. & Incomplete abortion & 29 & 14.5 \\
5. & Septic abortion & 3 & 1.5 \\
6. & Recurrent abortion & 18 & 9.0 \\
\hline
\end{tabular}

Table (4): Distribution of the studied women by their risk factors of spontaneous abortion

\begin{tabular}{|l|c|c|}
\hline \multirow{2}{*}{\multicolumn{1}{|c|}{ Item }} & \multicolumn{2}{c|}{ Total } \\
& $\mathbf{2 0 0 ( 1 0 0 \% )}$ \\
\cline { 2 - 3 } & $\mathbf{N}$ & \% \\
\hline 1-Passive smoking & 95 & 47.5 \\
\hline 2-Medications & 26 & 13.0 \\
\hline 3-Uterine or cervical problems & 20 & 10.0 \\
\hline 4-Conception within 3mns & 17 & 8.5 \\
\hline 5-Physical trauma & 16 & 8 \\
\hline
\end{tabular}




\begin{tabular}{|l|c|c|}
\hline \multicolumn{1}{|c|}{ Item } & \multicolumn{2}{c|}{ 200(100\%) } \\
\cline { 2 - 3 } & $\mathbf{N}$ & \% \\
\hline 6-Multiple pregnancy" twins" & 15 & 7.5 \\
\hline 7-Stress & 6 & 3.0 \\
\hline 8-Congenital anomalies & 5 & 2.5 \\
\hline 9-Intra uterine device & 4 & 2.0 \\
\hline 10-Chromosomal abnormalities & 2 & 1.0 \\
\hline 11-Invasive prenatal tests(amniocentesis) & 1 & 0.5 \\
\hline 12-Hormonal imbalance & 1 & 0.5 \\
\hline 13-Sexual trauma & 1 & 0.5 \\
\hline 14- Negative RH & 1 & 0.5 \\
\hline More than one risk factor was mentioned. & & \\
\hline
\end{tabular}

Figure (1): Shows the age of studied women. Mean age was 28.20 years. There were $81.5 \%$ of patients between 20-35 years old.

Figure (2) Shows the educational level of the studied women. Illiteracy \& low level of education were among $54.5 \%$ of the studied women.

Figure (3): Shows the residence of the studied women. 90\% were from rural areas.

Figure (4): Shows the occupation of the studied women, $91 \%$ were housewives.

Figure (5): Shows the medical history of the studied women. Only $18 \%$ were had medical history; hypertension was the common.

Table (1): Shows past obstetrical history among studied women. There were $42.0 \%$ of patients were multigravida and $47.5 \%$ of them were multipara, also, there were $43.0 \%$ had abortion less than 3 times. Mean value of spacing was 28.48 months, while $46.5 \%$ of patients had a spacing of $<=24$ months.

Table (2): Shows current obstetrical history among studied women. The mean gestational age at abortion was 13.70 weeks. Late abortion was among $57.5 \%$ of studied women (>12 weeks).

Table (3): Shows types of abortion among studied women; missed abortion constitutes $38.0 \%$.

Table (4): Shows risk factors for spontaneous abortion among studied women. There were $47.5 \%$ of women exposed to passive smoking and 13\% of them had history of taking medication for chronic diseases, other $10 \%$ had history of uterine or cervical problems.

\section{Discussion}

Spontaneous abortion is the most common type of pregnancy loss, affecting around one in four pregnancies. Identifying risk factors for spontaneous abortion are potentially important for public health. The aim of the current study was to identify the risk factors associated with spontaneous abortion.
About occupation the present study revealed that the majority of women with spontaneous abortion were housewives, this result disagrees with Park et al., (2017), who studied the prevalence of abortion and adverse outcomes among working women in Korea. They confirmed that the working women have a higher risk for abortion compared to non-working women. Other study done by Ameen \& Tawfeeq, (2015), who studied the risk factors of spontaneous abortion in Kirkuk city during the period from December 2010 to December 2012 they found high rate of spontaneous abortion especially among teaching and health professional occupations. The rational of these differences may be explained as the women in Upper Egypt work as helper for their husbands in their homes. They have long working hours in kitchen, they are lifting heavy objects, and standing for long periods. This physical work load can lead to spontaneous abortion.

In the present study most of women with spontaneous abortion were from rural areas, this result was not compatible with Ameen \& Tawfeeq (2015), they found the frequency of spontaneous abortion was higher in urban than in rural areas. Also Claire et-al., (2019), who studied the effect of air pollution on the spontaneous pregnancy loss on 1398 women at an academic emergency department in the Wasatch Front area of Utah between 2007- 2015. They found that short-term exposure to elevated levels of air pollutants was associated with higher risk for spontaneous pregnancy loss. The explanation of this finding is that recently usage of agricultural machinery and burning of agricultural wastes. May be a cause of air pollution in the rural areas.

One factor of spontaneous abortion in the present study was maternal age; high percentage of them was between 20-35 years old .This result not compatible with Magnus, et al., (2019), who studied All Norwegian women that were pregnant between 2009-2013 .They found that the risk of abortion was 
lowest in women aged 25-29 (10\%). At the same time agrees with Kamble \& Banerjee (2017), who studied spontaneous abortion and associated risk factors in India. They found that the age of women even in their early age (20 to 30 years) associated with spontaneous abortion because women in this age are suffers from physical, emotional and social trauma that are associated with spontaneous abortion. More than half of women in the present study were had no or low level of education; ( illiterate, read \& write \& basic education). This result agrees with Hegelund et al., (2019) they studied all registered pregnancies in Denmark during the period from 2000 to 2009 to investigate the effect of education on pregnancy outcomes. They found that the women with low educational attainment had a higher risk of abortion, stillbirth and preterm delivery.

Zheng et al., (2017), who studied factors associated with spontaneous abortion in Chinese population. They found "educational attainment was inversely associated with the risk of spontaneous abortion" when they compared with women in low educational attainment, women in higher educational attainment had a lower prevalence of spontaneous abortion. The explanation of this result illustrated that low level of education makes the woman unaware by importance of family planning services, preconception care, antenatal care, warning signs \& symptoms during pregnancy, which can lead to spontaneous abortion.

Nearly half on women in the present study were multiparae. This result agrees with Cohain et al., (2017), who studied all delivery room admissions from both Hadassah Medical Centers in Jerusalem Israel, 2004-2014. They found that abortion is common among parous women; $43 \%$ of parous women report having experienced one or more first trimester spontaneous miscarriages.

Nilsson et al., (2014), they studied the risk factors for spontaneous abortion from a prevention perspective, their results indicate that the majority of the study subjects were multigravida and multipara, so multigravida and multipara lead to weakness in the uterus and cervix this can lead to spontaneous abortion.

Nearly half on women in the present study were exposed to passive smoking. This result agrees with Pineles et al., (2014), who studied abortion and maternal exposure to tobacco smoke during pregnancy. They found that smoking increases the risk of miscarriage. Also, Ameen \& Tawfeeq (2015), found that the frequency of spontaneous abortion was higher with smoking, coffee intake and stress. Furthermore, the awareness about the health problems associated with the smoking may play an important role in decreasing the females interesting in smoking,
Nearly half of women in the present study had a period of spacing less than 24 weeks. Birgisson et al., (2015), who studied avoiding unintended pregnancy and abortions. This result agrees with Hrezog et al., (2019), who studied the association between unintended pregnancy and pregnancy loss In the Epilepsy Birth Control between 2010-2014, they found that unplanned pregnancy may double the risk of spontaneous fetal loss in women with epilepsy. Interpregnancy interval less than 1 year and conception age younger than 18 years or older than 37 years were also factors.

Nearly half of women in the present study had a history of previous abortion/s. this finding agrees with McPherson, (2016), who studied recurrence of stillbirth and second trimester pregnancy loss. He found that women experiencing multiple losses frequently had both second trimester miscarriages and stillbirths. Also, Fadhil, (2014), who studied the environmental effects on women's with spontaneous abortion in Chufa. He reported in her study that the majority of the women reported "previous abortion", and they are accounted 102(51\%) of the study sample.

\section{Conclusion}

This study concluded that the risk factors associated with spontaneous abortion were non-working women, rural residence, age between 20-35 years old, no or low-level education; (illiterate, read \& write \& basic education), multipara, hypertension, passive smoking, spacing of $\leq 24$ weeks, missed abortion, history of previous abortion/s.

\section{Recommendations}

- Applying Pre-conceptual counseling \& care for married women.

- Applying prenatal counseling and care for all pregnant women.

- Further studies to confirm the results of this study.

\section{References}

1. Amen, K., \&Tawfeeq A., (2015): Occupational, Environmental and Lifestyle factors associated with spontaneous miscarriage in Kirkuk city, Tikrit, Medical Journal, Vol. (20), No .(1),Pp.48-54.

2. Andersen, L., Jørgensen, J., Jensen, T., Dalgård, C., Barington, T., Nielsen, J., (2015): Vitamin D insufficiency is associated with increased risk of first-trimester spontaneous abortion in the Odense child cohort.Pp:633-638.

3. Birgisson, N., Zhao, Q., Secure, G., Madden, T., \& Peipert, J., (2015): Preventing 
unintended pregnancies and abortions: The contraceptive choice project in review. J Woman's Health (larch MT), Vol. (24), No.(5), Pp. 349-353.

4. Catalano, P., Gabbe, S., Niebyl, JR., Simpson, J., (2017): Normal and Problem Pregnancies, Abortion risk factors, 7th ed. Philadelphia, Elsevier, chap 41, P1320.

5. Center for disease control and prevention, (2012): Type 1 or type 2 diabetes and pregnancy: Available at: http://www.cdc.gov/pregnancy/diabetes types.HTML. [Accessed25August 2018].

6. Claire, P., Leiser, M., Heidi, A., Hanson, D., (2019): Acute effects of air pollutants on spontaneous pregnancy loss, a case-crossover study. Fertility and Sterility, Volume 111, Issue 2, February 2019, Pages 256-257.

7. Cohain, J., Buxbaum, R., Mankuta, D., (2017): Spontaneous first trimester miscarriage rates per woman among parous women with 1 or more pregnancies of 24 weeks or more. BMC Pregnancy Childbirth. 2017, Vol.(17),No.(1),Pp.437. Epub 2017 Dec 22.

8. Costello, G., (2013): What is spontaneous abortion? Available at: http://www.mergerwatch.org/ . . . /pdf. [Accessed20 August 2018].

9. Dugas, C., \&Slane, V., (2019): Miscarriage: National center of biotechnology information, US, National library, Stat Pearls Publishing LLC.

(http://creativecommons.org/licenses/by/4.0/).

10. Fadhil, S., (2014): Environmental effects on women's with spontaneous abortion: journal of Chufa for nursing science, vol. (4), No.(1), Pp. $1-12$.

11. Hegelund, E., Poulsen, G., Mortensen, L., (2019): Educational Attainment and Pregnancy Outcomes: A Danish Register-Based Study of the Influence of Childhood Social Disadvantage on Later Socioeconomic Disparities in Induced Abortion, Spontaneous Abortion, Stillbirth and Preterm Delivery, Maternal \& child health journal. First Online: 05 January 2019.

12. Herzog, A., Mand.le, H., MacEachern, D., (2019): Association of Unintended Pregnancy with Spontaneous Fetal Loss in Women with Epilepsy, Findings of the Epilepsy Birth Control Registry. JAMA Neurons, Vol. (76), No. (1),Pp.50-55.

doi:10.1001/jamaneurol.2018.3089.

13. Hobel, C., Williams, J., Hacker, N., Gambone, J., (2016): Essentials of Obstetrics and Gynecology, 6th ed. Philadelphia, Elsevier, chap 7, p 512.

14. Jibril, U., Kayoed, O., Umar, A., Abu Baker, I.\& Blessing, N., (2014): Spontaneous abortion among women admitted in to Gynecology words of three selected hospitals in Maiduguri, Nigeria: International journal of nursing and midwifery, vol.(6),No. (2), Pp. 24-31.

15. John, C., Peruzzi. (2016): Recurrent early pregnancy loss, [Cited 2016, October 13] available from: http://www. emedicine.medscape.com/article/260495overview.

16. Kamble, G., \& Banerjee, M., (2017): Spontaneous abortion and associated risk factors in India: a brief review; Women's health volume 4, issue 4, Pp.1-4.

17. Magnus, M., Wilcox, A., Morken, N., Weinberg, C., Håberg, S., (2019): Role of maternal age and pregnancy history in risk of miscarriage: prospective register-based study, BMJ. 2019; 364:1869. Epub 2019 Mar 20.

18. McPherson, E., (2016): Recurrence of stillbirth and second trimester pregnancy loss. Am J Med Genet A. 2016; 170 A (5):1174. Epub 2016 Mar 5 .

19. National institute for health and care excellence, (2012): Ectopic pregnancy and spontaneous abortion: diagnosis and initial management in early pregnancy of ectopic pregnancy and spontaneous abortion. Available at: https://www.nice.org.uk/ guidance/cg154. [Accessed10 September 2018].

20. Nilsson, S., Andersen, P., Larsen, K., \& Andersen, A., (2014): Risk factors for spontaneous abortion from a prevention perspective: a nationwide follow-up study .Royal college of obstetricians and gynecologists, Pp.1375-1385.

21. Park, C., Kang, M., Kim, D., (2017): Prevalence of abortion and adverse pregnancy outcomes among working women in Korea: A cross-sectional study. Plows One. November 20, Vol. (12), No.(11): e0188673.

22. Pineles, B., Park, E., Samet, J., (2014): Systematic review and meta-analysis of miscarriage and maternal exposure to tobacco smoke during pregnancy. Am J Epidemiol.2014, Vol. (179), No.(7),P.807. Epub 2014 Feb 10.

23. Pour Mohammadi E., (2015): Spontaneous abortion risk linked to lifestyle. Available at: http://timesofoman.com/article/65861/oman/hea lth/oman-health- healthy-lifestyle-can-reducespontaneous abortion-risk. [Accessed 11September 2018]. 
24. Rodriguez, C., (2015):5 Steps to decreasing the chance of recurrent spontaneous abortions, Natural fertility info. Available at http://naturalfertility-info.com/ preventing-spontaneous abortion.[Accessed at12 September 2018].

25. Romero, S., Geiersbach, K., Paxton, C., Rose, C., Schuster man, E., branch, D., \& Silver, M., (2015): Differentiation of genetic abnormalities in early pregnancy loss. Ultrasound in obstetrics and gynecology, Pp.8994.

26. Smith, P., Smith, D., Toole, O., Cooper, N., Coomarasamy, A., \& Clark, T., (2019): Outcomes in prevention and management of miscarriage trials: a systematic review. BJOG Jan, Vol. (126), No. (2),Pp.176-189.doi: 10.1111/1471-0528.15528.

27. Spontaneous abortion Association, (2015): Spontaneous abortion. Available at: http://www.spontaneous abortion association.

28. Tulandi, T., \& AlFozan, H., (2019): Spontaneous abortion: Risk factors, etiology, clinical manifestations, and diagnostic evaluation, Up To Date Term of Use, Inc.

29. Zheng, D., Litchi, W., \& Tang, K., (2017): Factors associated with spontaneous abortion: a cross-sectional study of Chinese populations; reproductive health, Pp:1-9. 